\title{
Chiral Phosphoric Acid Diesters as Ligands in Asymmetric Transition Metal Catalyzed Hydrogenation
}

\author{
Manfred T. Reetz ${ }^{*}$, Thorsten Sell, and Richard Goddard
}

Abstract: A chiral phosphoric acid diester, specifically the BINOL-based derivative, has been used for the first time in Rh-, Ir-, and Pd-catalyzed hydrogenation of olefins and imines, giving ee-values of up to $85 \%$.

Keywords: Asymmetric catalysis · Chirality · Hydrogenation · Iridium · Palladium · Phosphorus ligands . Rhodium

Recently monodentate phosphorus compounds have emerged as cheap and effective ligands in Rh-catalyzed olefin hydrogenation; BINOL-based monophosphites [1], monophosphoramidites [2], and monophosphonites [3] being prime examples. Moreover, we have recently established a new concept in combinatorial asymmetric catalysis based on the use of mixtures of chiral monodentate ligands such as phosphonites and phosphites [4][5]. Although a number of reports concerning the synthesis and coordination chemistry of chiral phosphoric acid diesters have appeared [6][7], to date these compounds have not been employed as ligands in asymmetric transition metal catalyzed hydrogenation. In this paper we present the first results concerning this possibility, the focus being on the BINOLbased derivative $\mathbf{1}$ which can be considered to be in equilibrium with its phosphite tautomer. Although the equilibrium lies far on the left side (as in the case of most other chiral and achiral phosphoric acid diesters), metal coordination can occur at the lone electron pair of the phosphite tautomer, much like in the case of the analogous phosphites [3].
Although the synthesis of racemic 1 has been claimed to occur cleanly by hydrolysis of the chlorophosphite 2 [8], we observed varying amounts of a compound that we identify as the anhydride 3 . The ${ }^{31} \mathrm{P}$ NMR spectrum of $\mathbf{1}$ shows a doublet at $\delta=14.4 \mathrm{ppm}\left({ }^{1} \mathrm{~J}_{\mathrm{PH}}=733.4 \mathrm{~Hz}\right)$, whereas that of $\mathbf{3}$ displays a singlet at $\delta=136 \mathrm{ppm}$ [9]. The use of only 0.5 equivalents of water changes the $\mathbf{1 / 3}$ ratio to $20: 80$, but so far 3 could not be isolated in pure form.
In contrast, treatment of $\mathbf{2}$ with tert-butanol according to a method useful in other cases [6b] afforded 1 quantitatively. In this case the tert-butyl-phosphite is formed as an intermediate which reacts with the liberated $\mathrm{HCl}$ to provide the product $\mathbf{1}$ along with easily separable tert-butylchloride [9]. Alternatively, heating 2 with formic acid according to an alternative method [10] also provided 1 in excellent yield (94\%) [9].
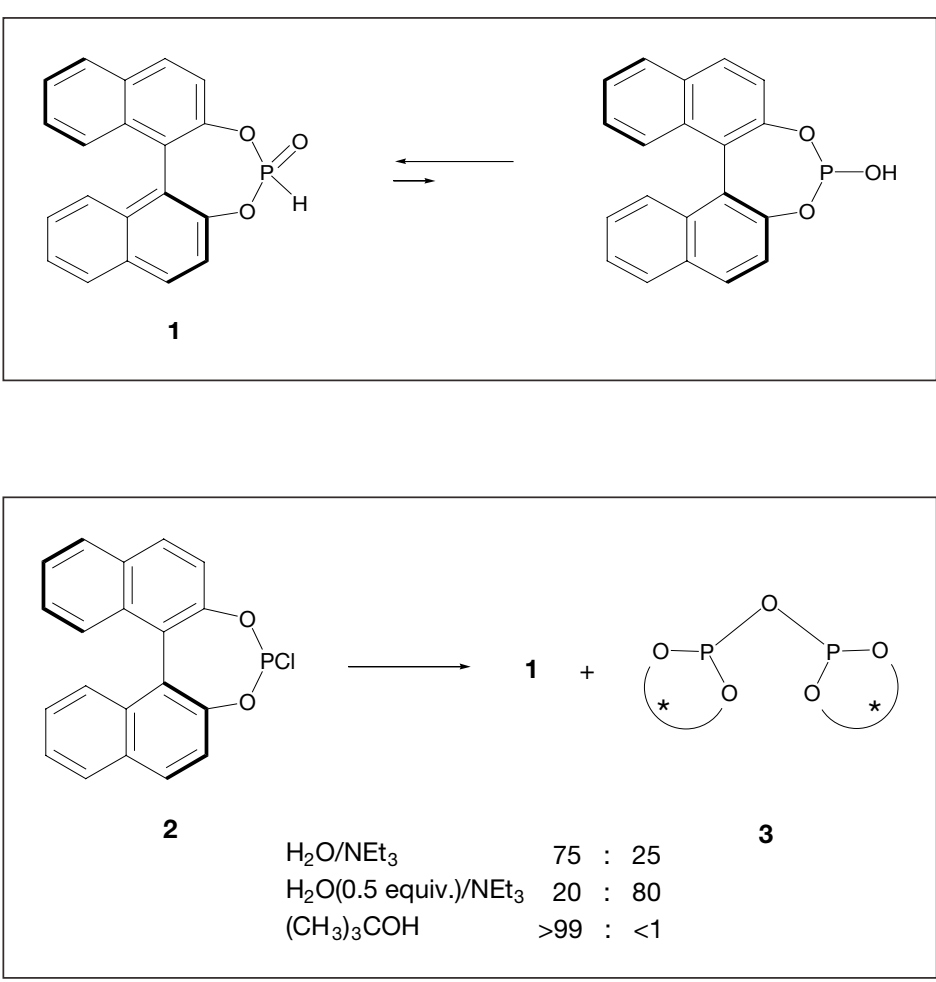
Upon reacting $\left[\mathrm{Rh}(\mathrm{cod})_{2}\right] \mathrm{BF}_{4}$ with 2 equiv. of $(S)-\mathbf{1}$ for $2 \mathrm{~h}$ and using the in situ formed Rh-complex as a catalyst in the hydrogenation of itaconic acid dimethyl ester 4 under standard conditions $(\mathrm{Rh} / \mathbf{4}=$ $1: 1000 ; 1.3$ bar $\left.\mathrm{H}_{2} ; 20 \mathrm{~h} ; \mathrm{CH}_{2} \mathrm{Cl}_{2}\right)$ [3], quantitative conversion to $(S)-\mathbf{5}$ was observed, with an ee of $85 \%$. This is only slightly lower than in the case of the analogous BINOL-based methyl phosphite $(e e=89 \%)$ [3].

Although structural and mechanistic studies have not been completed, we speculate that coordination at the lone electronpair of phosphorus in the phosphite tautomer will acidify the hydroxy function, which could then play a role in catalysis by forming H-bonds with the substrate. We also studied a more difficult substrate $\mathbf{6}$ using iridium catalysis [11]. The precatalyst formed by reacting $[\operatorname{Ir}(\operatorname{cod}) \mathrm{Cl}]_{2}$ with 1 showed a dependency on solvent and amount of ligand (Table). In all cases conversion was quantitative, the highest ee reaching $49.7 \%$ in toluene (entry 5), whereas in ethanol enantioselectivity is reversed (entry 6).

Application of palladium catalysis [12] $\left(\mathrm{Pd}(\mathrm{OAc})_{2}+2\right.$ equiv. of $1(5 \mathrm{~mol}-\%)$;

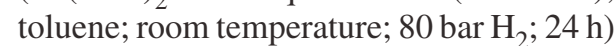
in the hydrogenation of $\mathbf{6 a}$, resulted in essentially racemic 7a. In contrast, $6 \mathbf{b}$ was hydrogenated under these conditions to form $\mathbf{7 b}$ with an $e e$ of $38.5 \%(R)(100 \%$ conversion). Interestingly, the anhydride 3 (containing 20\% of 2) led to an ee of $75.6 \%$ $(S)$, which means an inversion of enantioselectivity. This begins to compete with other methods [11-13]. It has been reported that the BINOL-based phenylphosphonite leads to racemic products in these cases [11].

Although we have not yet been able to characterize the above metal complexes unambiguously, we succeeded in obtaining crystals of a platinum complex 9 prepared by reacting $\mathrm{PtCl}_{2}\left(\mathrm{CH}_{3} \mathrm{CN}\right)_{2}$ with $(S)-2$ and hydrolyzing $[6 \mathrm{f}, \mathrm{g}]$ the bis-adduct $\mathbf{8}$ in the presence of $\mathrm{NEt}_{3}$ [9]. The crystal structure (Fig. 1) shows a cis-coordination at phosphorus in the phosphite tautomer. Deprotonation by $\mathrm{Et}_{3} \mathrm{~N}$ has occurred with formation of $\mathrm{HN}^{+} \mathrm{Et}_{3}$, which is strongly hydrogen bonded to $\mathrm{O}^{-}[14]$.

In summary, we have shown for the first time that a chiral phosphoric acid diester [15] can be used in Rh-, Ir-, and Pd-catalyzed hydrogenation. Since a large number of chiral diols are available for the potential synthesis of the corresponding phosphoric acid diesters, the stage is set for further studies, including our combinatorial approach [4] in which compound $\mathbf{1}$ (or an analog) is mixed with other types of monodentate P-ligands.

Received: April 1, 2003
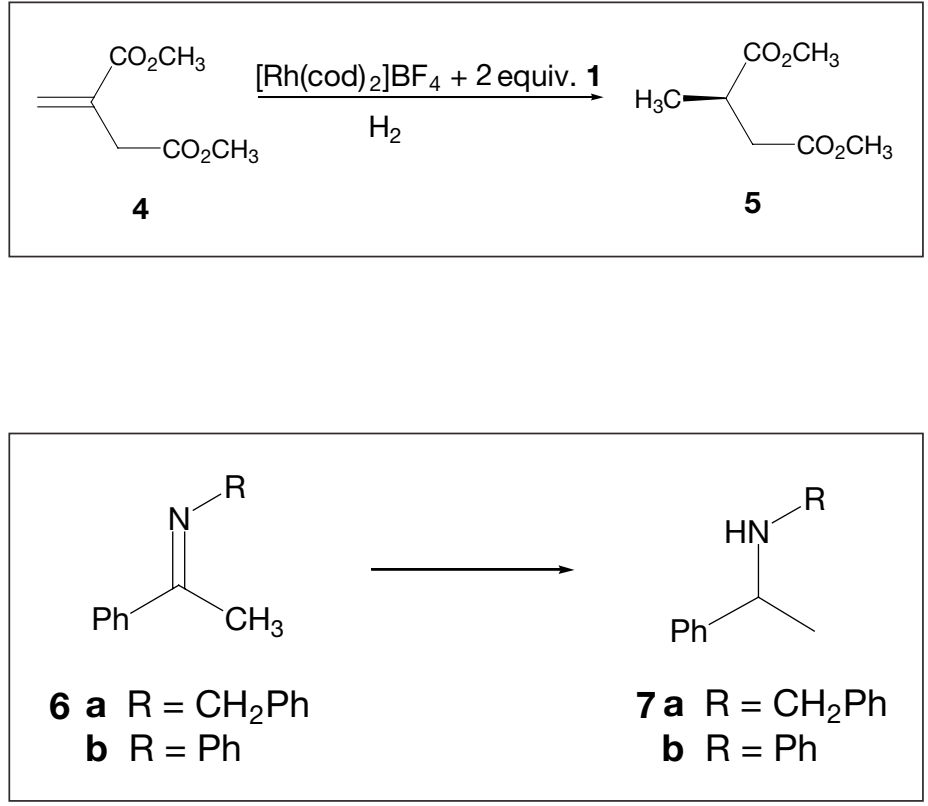

Table. Iridium-catalyzed hydrogenation of imine $6 \mathrm{a}^{\mathrm{a}}$ using $\mathbf{1}$ as the ligand

$\begin{array}{llll}\text { Entry } & \text { Ligand : Ir } & \text { Solvent } & \text { \%-ee (config.) of 7a } \\ 1 & 2 & \mathrm{CH}_{2} \mathrm{Cl}_{2} & 42.2(R) \\ 2 & 1 & \mathrm{CH}_{2} \mathrm{Cl}_{2} & \text { racemic } \\ 3 & 3 & \mathrm{CH}_{2} \mathrm{Cl}_{2} & 40.1(R) \\ 4 & 4 & \mathrm{CH}_{2} \mathrm{Cl}_{2} & 39.3(R) \\ 5 & 2 & \text { toluene } & 49.7(R) \\ 6 & 2 & \text { ethanol } & 12.8(S) \\ 7 & 2 & \text { THF } & 29.2(R)\end{array}$

aPrecursor: $[\mathrm{Ir}(\mathrm{cod}) \mathrm{Cl}]_{2}$; conditions: substrate/catalyst $=33: 1,80 \mathrm{bar}_{2}$, $48 \mathrm{~h}$, room temp.; conversion: $100 \%$.
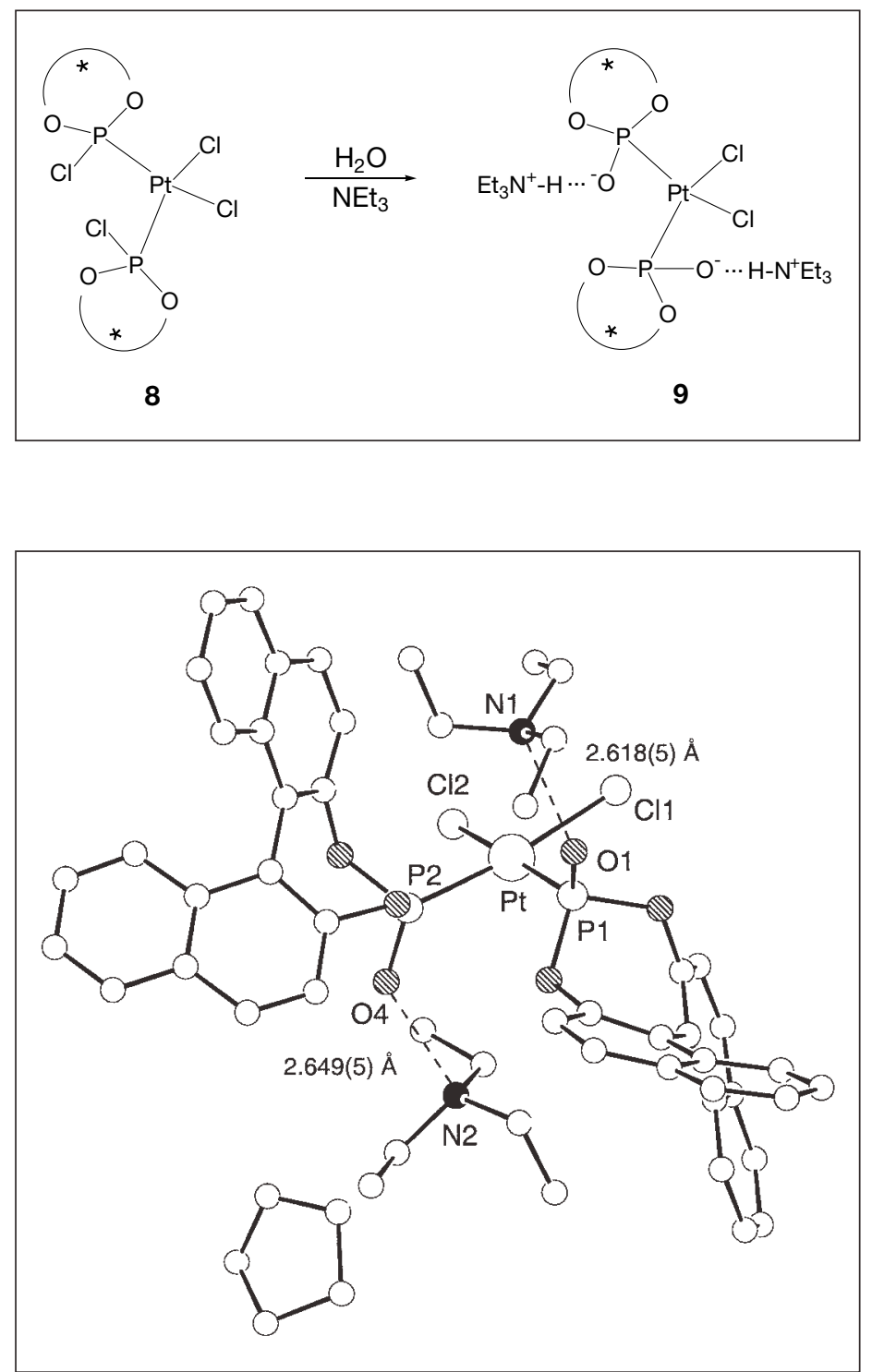

Fig. 1. Crystal structure of the Pt-adduct 9, showing the $\mathrm{N}-\mathrm{H}^{\prime \cdots} \mathrm{O}^{-}$ hydrogen bonding interactions. 
[1] a) M.T. Reetz, G. Mehler, Angew. Chem. 2000, 112, 4047; Angew. Chem. Int. Ed. 2000, 39, 3889; b) M.T. Reetz, G. Mehler, A. Meiswinkel, T. Sell, Tetrahedron Lett. 2002, 43, 7941 .

[2] a) M. van den Berg, A.J. Minnaard, E.P. Schudde, J. van Esch, A.H.M. de Vries, J.G. de Vries, B.L. Feringa, J. Am. Chem. Soc. 2000, 122, 11539; b) A.J. Minnaard, M. van den Berg, E.P. Schudde, J. van Esch, A.H.M. de Vries, J.G. de Vries, B.L. Feringa, Chim Oggi 2001, 19, 12.

[3] a) M.T. Reetz, T. Sell, Tetrahedron Lett. 2000, 41, 6333; b) C. Claver, E. Fernandez, A. Gillon, K. Heslop, D.J. Hyett, A. Martorell, A.G. Orpen, P.G. Pringle, Chem. Commun. 2000, 961.

[4] M.T. Reetz, T. Sell, A. Meiswinkel, G Mehler, Angew. Chem. 2003, 115, 814; Angew. Chem. Int. Ed. 2003, 42, 790.

[5] Following our report [4], Feringa has described further examples using phosphoramidites (private communication), to be published in Org. Biomol. Chem.

[6] a) H.D. Block in 'Houben Weyl, Organische Phosphorverbindungen', Ed. M. Regitz, Thieme-Verlag, Stuttgart, 1982 , Bd. E1, p. 322 ff; b) N.K. Bliznyuk, L.D. Protosova, SU patent 455964, 1973; c) A. Munoz, C. Hubert, J.-L. Luche, J. Org. Chem. 1996, 61, 6015; d) B. Walther, Coord. Chem. Rev. 1984, 60, 67; e) D.M. Roundhill, R.P. Sperline, W.B. Beaulieu, Coord. Chem. Rev. 1978, 26, 263; f) D.E. Berry, K.A. Beveridge, G.W. Bushnell, K.R. Dixon, Can. J. Chem. 1985, 63, 2949; g) D.E. Berry, K.A. Beveridge, G.W. Bushnell, K.R. Dixon, A. Pidcock, Can. J. Chem. 1986, 64, 343; h) C.G. Arena, F. Nicolò, D. Drommi, G. Bruno, F. Faraone, J. Chem. Soc., Dalton Trans. 1996, 4357; i) J.A.S. Duncan, T.A. Stephenson, W.B. Beaulieu, D.M. Roundhill, J. Chem. Soc., Dalton Trans. 1983 1755 ; j) D.E. Berry, K.A. Beveridge, J. Browning, G.W. Bushnell, K.R. Dixon, Can. J. Chem. 1986, 64, 1903.

[7] (a) Enders has prepared the chiral phosphoric acid diester derived from TADDOL and used it in stoichiometric highly diastereoselective Michael additions to nitroolefins: D. Enders, L. Tedeschi, J.W. Bats, Angew. Chem. 2000, 112, 4774; Angew. Chem. Int. Ed. 2000, 39, 4605; (b) Alexakis has used the TADDOL-derived phosphoric acid diester in $\mathrm{Cu}$-mediated conjugate addition reactions of $\mathrm{Et}_{2} \mathrm{Zn}$, but the $e e$ turned out to be poor ( $e e=3-17 \%$ ), in contrast to other monodentate P-ligands: A. Alexakis, J. Burton, J. Vastra, C. Benhaim, X. Fournioux, A. van den Heuvel, J.-M. Leveque, F. Maza, S. Rosset, Eur. J. Org. Chem. 2000, 4011.

[8] N. Greene, T.P. Kee, Synth. Commun. 1993, 23, 1651.

[9] T. Sell, Dissertation, Ruhr-Universität Bochum, Germany, 2002.

[10] G.H. Birum (Monsanto Co), US patent 4070336, 1976.

[11] A. Martorell, C. Claver, E.J. Fernandez, Inorg. Chem. Commun. 2000, 3, 132.

[12] H. Abe, H. Amii, K. Uneyama, Org. Lett. 2001, 3, 313.
[13] See for example: a) D. Xiao, X. Zhang, Angew. Chem. 2001, 113, 3533; Angew. Chem. Int. Ed. 2001, 40, 3425; b) X. Zhang, D. Xiao, WO 01/14299 A1; c) J.G. de Vries, C. Lensink, E. Rijnberg, J. Mol. Catal. A: Chem. 1997, 116, 199; d) C.A. Willoughby, S.L. Buchwald, J. Am. Chem. Soc. 1994, 116, 8952.

[14] Crystal data for 9: $\left[\mathrm{C}_{40} \mathrm{H}_{24} \mathrm{Cl}_{2} \mathrm{O}_{6} \mathrm{P}_{2} \mathrm{Pt}\right]^{2-}$. $2\left[\mathrm{C}_{6} \mathrm{H}_{16} \mathrm{~N}\right]^{+} \cdot\left[\mathrm{C}_{4} \mathrm{H}_{8} \mathrm{O}\right]$, colorless prism from tetrahydrofuran, $\mathrm{M}_{\mathrm{r}}=1205.02$, monoclinic, space group $P 2_{1}, a=10.0204(4), b=$ $13.0816(5), \quad c=20.2168(8) \AA, \quad \beta=$ 102.104(2) $)^{\circ}, U=2591.2(2) \AA^{3}, Z=2, D$ $=1.54 \mathrm{gm} \mathrm{cm}^{-3}, F(000)=1224, \mu($ Mo$\mathrm{K}_{\alpha}$ ) $=2.927 \mathrm{~mm}^{-1}, T=100 \mathrm{~K}$, Siemens SMART diffractometer, $\omega$-scan, graphite monochromated Mo- $\mathrm{K}_{\alpha}$ radiation, $\lambda=$ $0.71073 \AA$, absorption correction $\left(T_{\min }=\right.$ $\left.0.39059, T_{\max }=0.78013\right), \theta_{\max }=33.9^{\circ}$, 28868 reflections measured, 14740 unique, of which $13490 \mathrm{I}>2 \sigma(\mathrm{I}), R_{\text {int }}=0.031$; programs SHELXS-97 and SHELXL-97 from G.M. Sheldrick, University of Göttingen, 1997; 631 parameters, Chebychev weights, $R(F)=0.035[I>2 \sigma(I)], w R(F 2)=$ 0.078 (all data), $\mathrm{H}$ atoms riding, Flack parameter $=0.005(4), \Delta \rho_{\max / \min } 2.67 \mathrm{e}$ $\AA^{-3} /-1.87$ e $\AA^{-3}$. CCDC-207145.

[15] Similar results were observed upon using the octahydro-BINOL derived ligand [9]. 